\title{
Dr. Joy Richards, 2010 Recipient, Margret Comack Award in Nursing Leadership
}

\section{|} n early November, Dr. Joy Richards was awarded the Margret Comack Award in Nursing Leadership at the 2010 HealthAchieve convention. Dr. Richards is a well-known and highly respected nurse leader who has held a range of significant management positions. She recently shared some of her personal experience as a nurse leader with the Canadian Journal of Nursing Leadership.

\section{Background}

Dr. Richards is the incoming vice-president professional affairs and chief nursing executive at University Health Network in

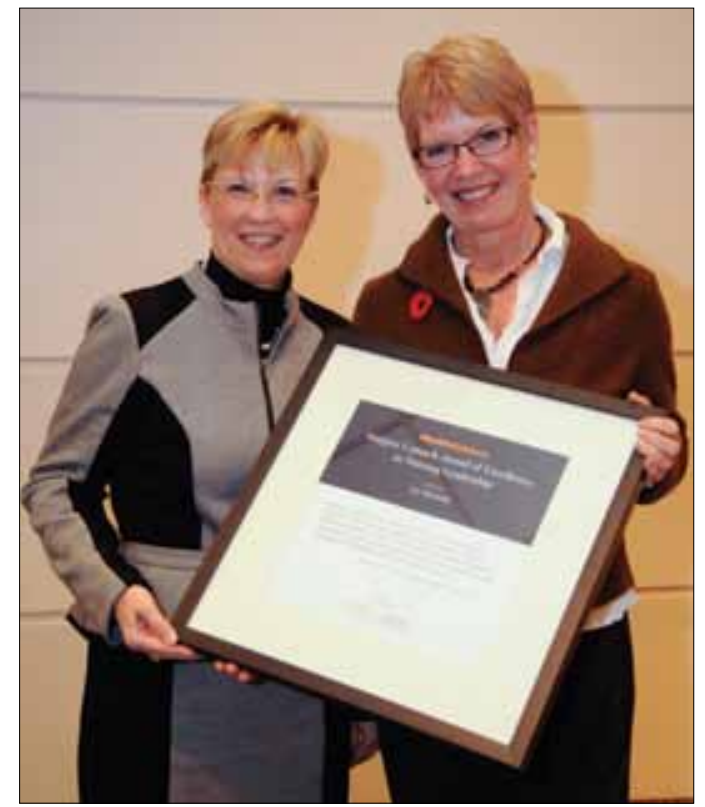

Joy Richards (left) with Margret Comack

Toronto, an academic health science centre comprised of three hospitals - Toronto General, The Princess Margaret Hospital and Toronto Western Hospital. She is also the immediate past-president of the Academy of Canadian Executive Nurses, and holds clinical appointments at the University of Toronto, Faculty of Nursing, York University Faculty of Nursing and Humber College in Toronto.

Her previous experience includes progressive senior nursing management positions in the acute care and long-term care sectors, nursing education and nursing informatics. 
Dr. Richards graduated from the University of Toronto with a bachelor of science degree in nursing in 1981, and a master's degree nursing in 2000. She then went on to complete a master of arts degree in human and organizational systems from Fielding Graduate University in Santa Barbara, California in spring 2005. She is also a graduate of the Queen's University Executive Program and a Johnson \& Johnson Wharton Fellow, University of Pennsylvania. Dr. Richards completed her doctoral studies in 2008 in human and organizational development at Fielding Graduate University; her dissertation focused on exploring and understanding the development and practice of feminine courage in leadership. Her particular interests, focus and passion are in the area of nursing leadership, quality of work life environments and the development of practice settings, with a special focus on excellence in geriatric care.

\section{What have you found to be the most important attributes for leadership? Why?}

There are several important attributes that I feel are vital for successful leadership today. The first is a strong understanding of complexity science, paradox and the ability to see disorder as a medium for innovation and creativity. From my perspective, the behaviours of a strong leader are gained not from the rigid boundaries of organizational structures and job descriptions but from information arising out of deep, natural processes of growth and self-renewal. The second important leadership attribute is to be grounded in one's personal values. The ethical and moral choices we face every day as nurse leaders require both commitment and conviction to understand the consequences of turning away from a difficult or fearful situation. The third attribute is that of perseverance. Leaders who persevere are what Meg Wheatley calls "edge-walkers": people called upon to walk on the difficult and often razor-sharp edge of chaos - that ambiguous space where commitment is juxtaposed against doubt. Creativity, imagination and rejuvenation live in this space, and it takes the fourth attribute - courage - to live and work there.

\section{How would you describe your leadership style? Has it evolved over your career, and if so, what were the most important influences?}

My leadership style has been evolving over the years, as I have matured and learned from my successes and failures. Mentors, as well as my passion for lifelong advanced learning, have greatly influenced my thinking on leadership; in particular, I learned a lot through the exploration of the concept of courage during my $\mathrm{PhD}$ studies. I also make a point of reading broadly - especially biographies of great male and female leaders. Based on my learnings about developing higher orders of complexity of thought, I work hard at being open, listening with "big ears," as the jazz musicians say, and creating safe space to allow voices of "the other" to be heard. This is how new possibilities can unfold. I am constantly aware of my choices as a leader, and my style reflects this: I can open up or shut down conversations, I can withdraw into safety or step forward towards a challenge, I can turn towards or away from a difficult issue, and I can consistently look 
inward towards self-reflection or outward towards blame. I work at being open to things outside my narrow sense of self. Leadership is about cultivating the ground beyond ourselves, inviting others to participate in the journey together.

\section{What is the most satisfying aspect of your role as a nurse leader? What has been the most disappointing?}

The absolute most satisfying aspect of my role is seeing and being part of others' growth and development! Mentorship, coaching and being alongside others during times of challenge and joy feed my soul and provide a shared experience that always transforms both of us in the interest of improving patient care and quality staff environments. Also, staying connected at the point of care is important to me. Being with patients and their families keeps me focused on what is important in the work.

The most disappointing thing for me is the slowness of much-needed change within the healthcare system and the lack of the patient's voice within these changes. Despite years of research, evidence and rhetoric, I perceive a widespread sense of passivity or inertia among many leaders. There seems to be reluctance or incapacity to act in order to solve problems by re-imagining situations. By this I mean engaging in the full sense of ideas. Real ideas are filled with uncertainty. To keep them alive, you must constantly question them. Re-imagining, in my mind, is important because ideas are the driving force of the most powerful and longestlived actions. This means looking beyond the reactive world of managers managing situations with narrow, utilitarian thoughts. As leaders, we need to believe we are capable beyond measure of filling the roles with which we have been entrusted. I am troubled when I see many leaders living out their roles in what is akin to sedated despair. As a result, many leaders downsize their role into one that is more passive or reactive. We need to regain our self-confidence, sophistication and ambition as nurse leaders. We need to get on with creating, building, risking and owning a sense of renewed and focused purpose in our actions.

\section{What do you consider to be the most significant challenge facing nurse lead- ers over the next few years?}

I believe that the next three to five years are going to be increasingly difficult for nurse leaders. Funding constraints, increased accountability, an aging workforce, health human resource issues and increased complexity of patient care will have us reliving the 1990s if we are not careful and learn from our past mistakes. I have both sensed and observed a slow decline in leadership self-confidence, sense of purpose and direction that has perhaps led to a myriad of passive actions or inactions that are undoing, or at the very least slowing down, our capacity to build a better healthcare system. As leaders, we cannot slip into the vacuum behind other people's actions. We cannot afford to imitate the surface appearance, not fully 
engaging in the reality of other people's actions. As nurse leaders, we need to cultivate a renewed self-confidence to feel that we can be at the origin of new ideas, or at least speak up for new ideas, and therefore lead the way in unusual developments. Nurses have always been at the forefront of helping society shape itself in the spirit of public good. Nurses' voices are needed now more than ever.

\section{What was the best piece of advice you were ever given in your career? Why?}

There are two pieces of advice I hold close to my heart - actually, both having to do with shoes, funnily enough, which are also close to my heart! The first piece of advice is to always walk in your own shoes. There are many fine leaders and mentors we want to emulate in our roles, but we cannot be them, no matter how hard we try. We can walk alongside their footprints, even sometimes placing our feet within their imprint, but we must be comfortable in our own shoes, find our own unique voice and forge our own unique path. Only by wearing our own shoes will we bring authenticity to our leadership roles. The second important piece of advice is to "look long and far." We need to keep our eyes on the horizon rather than constantly looking down at our shoes, as often our feet are moving but staying in the same place. This advice I hold dear because it is too easy to get caught up in the drama of the everyday minutiae and mistake this for something of great importance. In looking down at our feet, we deplete our energy and lose sight of our passion and our vision. We miss opportunities. We need to hold true to our horizon in the distance so we don't lose our way.

\section{What piece of advice would you like to pass along to aspiring leaders?}

Nothing worth doing in life is easy, and life and leadership are not linear, with a beginning, middle and an end. Rather, we live and lead in patterns of light and darkness, success and failure, commitment and doubt, and courage and fear. These paradoxes are both a normal part of living and create new opportunities. Each aspiring leader needs to find his or her shoes and wear them proudly. Don't be afraid to think. Don't be afraid to fail. Don't be afraid to speak truth to power. Don't settle for mediocrity and mendacity. Live and lead from the edge... strive to be an "edge walker"! 